\title{
Booms and Busts in a Housing Market with Heterogeneous Agents
}

\author{
G. Ascari* \\ University of Oxford and University of Pavia \\ N. Pecora ${ }^{\dagger}$ \\ Catholic University, Piacenza, Italy \\ A. Spelta \\ Catholic University, Milano, Italy
}

July 5, 2016

\begin{abstract}
We develop a dynamic partial equilibrium model of the housing market, where the dynamics of the house price is determined by the interaction between chartists and fundamentalists. The model endogenously generates episodes of boom and bust in the house price and can replicate the recent US house price dynamics, and points to endogenous and exogenous behavioral factors as the main determinants of such dynamics.
\end{abstract}

Keywords: housing market, heterogeneous expectations, boom-bust.

JEL codes: E03, E32, G01.

*guido.ascari@unipv.it

†nicolo.pecora@unicatt.it

$\ddagger$ alessandro.spelta@unicatt.it 


\section{Housing Market with Heterogeneous Agents}

G. Ascari $^{1}$

University of Oxford and University of Pavia

N. Pecora ${ }^{2}$

Catholic University, Piacenza, Italy

A. Spelta ${ }^{3}$

Catholic University, Milano, Italy 


\section{Introduction}

Since the late 1990's a dramatic increase in housing prices has been observed in most of the countries around the world. It seems impossible to explain this phenomenon merely from a rational point of view because fundamentals such as real rents or construction costs do not match up with this large price boom. Shiller $(2005,2008)$ suggested that the same forces of human psychology driving financial markets could also have the potential to affect other markets, especially the housing market. Recurrent boom-bust house price cycles generate the need for an endogenous explanation for such phenomena, possibly incorporating bounded rationality into housing market modeling.

In this paper, we try to take on this challenge. We aim to build a stylized model of the housing market with no rational expectations able to produce endogenous prolonged movements in the house prices. The house is an asset that can be collateralized and whose price can be driven both by fundamentals and by animal spirits. Note that ample empirical evidence exists to show that agents generally act in a bounded rational way (e.g., Kahneman and Tversky, 1973, Hommes, 2011).

To do so, we build on the model of Adam, Marcet and Kuang (2011) but we modify it in two ways. First, we introduce a different timing between demand and supply to account for the fact that it takes time to build new houses. So while households take their decision daily, the supply is based on a quarterly frequency. Second, we change the way agents form expectations. Instead of using Bayesian learning, we employ an Agent-Based ${ }^{4}$ framework of chartism and fundamentalism, where agents use different adaptive learning rules to forecast the future house price. Household are maximizing agents, and they can be either chartists, believing in a continuation of the recently house price trend, or fundamentalists, who expect a reversal towards the fundamental value. We follow Kontonikas and Montagnoli (2006), Westerhoff (2012), De Grauwe and Kaltwasser (2012), Lengnick and Wohltmann $(2013,2016)$ and Naimzada and Pireddu (2013) by assuming that household cannot identify the true fundamental price. Fundamentalists therefore are forced to proxy the fundamental value by the information they receive about the underlying conditions of the housing

supply. Their perceived house price fundamental value, therefore, can be interpreted as "fundamental" in the sense that it depends on "fundamentals" and it moves at low frequency, following 
housing supply which is constant over a quarter. Moreover, they continuously evaluate these two different strategies according to past performance; this leads to endogenous shifts in the relative shares of the two groups (chartists vs. fundamentalists). These shifts have large effects on the house price dynamics. When chartists dominate the market, house price can sharply deviate from the underlying fundamental value but, if the animal spirits change, the market will be dominated by fundamentalists and the price will revert towards the fundamental value ${ }^{5}$.

In this paper we show that, by embedding into the model an Agent-Based mechanism of evolutionary selection of expectation rules based on reinforcement learning, it is possible to generate an endogenous creation of boom-and-bust dynamics. By relaxing the rational expectation hypothesis, the evolutionary selection of the two different forecasting rules causes waves in the relative shares of the two groups of agents who amplify and protract initial shocks. We use the partial equilibrium model of Adam, Marcet and Kuang (2011), because it allows us to find a closed form solution for the housing demand function and thus to identify and analyze the relevant feedback and amplification mechanisms in the model.

Moreover, the model is able to replicate the recent boom-and-bust cycle in the US house prices. We are able to discuss three determinants that the literature suggests as potential sources of the recent boom-and-bust cycle in the US house prices. First, the "Greenspan put" explanation that claims that the house price boom would have been caused by persistent low levels in the interest rate. Second, an explanation based on an overall loosening of credit standards that allowed more borrowing from the households, followed by a sudden freeze of credit at the onset of the crisis (e.g., Favilukis, Ludvigson and Van Nieuwerburgh, 2010, Mian and Sufi, 2009, Benito and Mumtaz, 2009, Eickmeier and Hofmann, 2013). Following Justiniano, Primiceri and Tambalotti (2013) we can call it a "credit liberalization" cycle narrative. The third, instead, refers to an explanation not based on fundamentals, but on exogenous forces modeled as a change in households' preference and housing demand. Justiniano, Primiceri and Tambalotti (2013) call it a "valuation" story; we could also name it a "behavioral" story because it is based on a change of behavior of agents unrelated to fundamentals.

Our analysis suggests that by far the most important factor in the recent boom-bust dynamics 
of the house price in the US is a change in households' preference and housing demand. On the contrary, narratives based on "fundamentals" as the interest rate behavior or the credit market liberalization appear to be unimportant in our framework.

The paper is constructed as follows. Section 2 presents the first building block of our model based on Adam, Marcet and Kuang (2011). Section 3 explains the Agent-Based block of our model and the chartists and fundamentalists behavioral rules. Section 4 shows the results of simulations. Section 5 investigates the ability of the model to replicate the recent house price dynamics taking into consideration the real interest rate dynamics, the credit tightness and a preference shock for housing demand. Section 6 concludes.

\section{The Model}

\subsection{The Household Problem}

The economy is populated by a unit mass of households with identical preferences but potentially different and not rational beliefs, indicated by $\tilde{E}_{t}(\cdot)$, that we will specify later in Section 3.1 when we will introduce the distinction between chartists and fundamentalists. Households take daily decisions ( $t$ stands for days) and their preferences are described by the following inter-temporal quasi-linear utility function:

$$
\tilde{E}_{0} \sum_{t=0}^{\infty} \delta^{t}\left(c_{t}+j_{t} \log h_{t}\right)
$$

where $c_{t}>0$ is the daily consumption of goods, $h_{t}$ is the daily consumption of housing services, $\delta \in(0,1)$ is the discount factor, and $j_{t}$ is a preference shock for housing demand.

The household period-by-period budget constraint is:

$$
c_{t}+\left[h_{t}-(1-\tilde{d}) h_{t-1}\right] Q_{t}+R_{t} b_{t-1}+k_{t}=y_{t}+b_{t}+k_{t-1} p_{t}
$$

where $Q_{t}$ is the house price at time $t, \tilde{d} \in[0,1)$ is the daily depreciation rate of a house, $b_{t}$ is the household new loans, $R_{t}$ is the gross real interest rate on loans and $y_{t}$ is income, which is exogenous. ${ }^{6}$ The capital stock, $k_{t}$, is owned by the households who rent it to house builders for 
production. Capital fully depreciates in one period and its remuneration is $p_{t}$.

As in Kiyotaki and Moore (1997), households are allowed to borrow from banks subject to a borrowing constraint:

$$
b_{t} \leq \theta \frac{Q_{t}}{R_{t}} h_{t}
$$

The parameter $\theta$ represents the share of assets that can be collateralized. It is fixed and cannot exceed the house value after the depreciation: hence $\theta \in(0,1-\tilde{d}]$. Kiyotaki and Moore (1997) interprets a value of $\theta$ lower than one as reflecting the cost the lenders suffer in case of default. A growing house price relaxes the collateral constraint, implying that the households will have greater access to credit.

Households maximize their utility function (1) subject to the sequence of budget and borrowing constraints (2-3). From the first order conditions, it is possible to derive the households' demand for housing services:

$$
h_{t}^{d}=j_{t}\left[\left(1+\delta \theta-\frac{\theta}{R_{t}}\right) Q_{t}-(1-\tilde{d}) \delta \tilde{E}_{t} Q_{t+1}\right]^{-1}
$$

The capital rented by the consumers to house builders should satisfy:

$$
\left(1-\delta p_{t+1}\right) k_{t}=0
$$

so that either $p_{t}=\delta^{-1}$ or $k_{t}=0$. Given the non-negativity constraint on capital, the quasi-linear utility function implies that at that price capital and consumption are not uniquely determined and agents are indifferent between increasing slightly the capital sold to firms at time $t$ in exchange for $\delta^{-1}$ more units of consumption at $t+1$. The capital supply offered by consumers is thus perfectly elastic, so that $k_{t}$ is determined by firm's demand at the market price of $p_{t}=\frac{1}{\delta}$.

Finally consumption can be obtained residually using the flow budget constraint:

$$
c_{t}=y_{t}+b_{t}-\left(h_{t}-(1-\tilde{d}) h_{t-1}\right) Q_{t}-b_{t-1} R_{t}-k_{t}-k_{t-1} \delta^{-1}
$$




\subsection{Housing Supply}

As said above, we assume that house builders operate quarterly $(q)$. The house builders borrow capital from the households in a competitive market and employ it as input in a simple decreasing return to scale production function:

$$
S_{q}^{h}=(\alpha \delta)^{-1} k_{q}^{\alpha}
$$

$k_{q}$ is the sum over a quarter of the daily capital received from household and $\alpha \in(0,1)$. The market for input is always in equilibrium and the price for capital is $p_{t}=\delta^{-1} \forall t, q$.

The firm chooses $k_{q}$ to maximize its profits, i.e., $\max _{k_{q} \geq 0} \tilde{E}_{q}\left(S_{q}^{h} Q_{q+1}-\delta^{-1} k_{q}\right)$, where $Q_{q+1}$ is the quarterly house price in the next quarter. ${ }^{7}$ The first order condition is:

$$
k_{q}=\left(\tilde{E}_{q} Q_{q+1}\right)^{\frac{1}{1-\alpha}} .
$$

In maximizing profits, house builders need to form expectations about the next quarter house price. We assume house builders have static expectations, so that: $\tilde{E}_{q}\left[Q_{q+1}\right]=Q_{q}$. The profit-maximizing input demand therefore becomes:

$$
k_{q}=\left(Q_{q}\right)^{\frac{1}{1-\alpha}}
$$

and substituting it into the production function we obtain the quarterly supply of new houses:

$$
S_{q}^{h}=(\alpha \delta)^{-1} Q_{q}^{\frac{\alpha}{1-\alpha}}
$$

The housing stock evolves according to:

$$
h_{q}=(1-d) h_{q-1}+S_{q}^{h}
$$

Note that this is an end-of-period definition of the housing stock. The stock of houses at the end of quarter $q$, thus available for consumption in the next quarter $q+1$, depends on the existing stock in the previous quarter, $h_{q-1}$, net of depreciation, plus the production of new houses in the quarter. $^{8}$ It follows that the stock of houses available for consumption in quarter $q$ is equal to the 
stock at the beginning of quarter $q$, that is, $h_{q-1}$.

After log-linearization, demand and supply read as:

$$
\begin{gathered}
\widehat{h}_{t}^{d}=\widehat{j}_{t}+\frac{Q h^{d}}{j}\left[(1-\tilde{d}) \delta \tilde{E}_{t} \hat{Q}_{t+1}-\left(1+\delta \theta-\frac{\theta}{R}\right) \hat{Q}_{t}-\frac{\theta}{R} \hat{R}_{t}\right], \\
\hat{S}_{q}^{h}=\frac{\alpha}{1-\alpha} \hat{Q}_{q} .
\end{gathered}
$$

The demand function in (12) depends positively from the preference for houses and from the expected future price, while negatively from the current price ${ }^{9}$ and from the interest rate. The housing supply is a positive function of the quarterly price.

Finally, log-linearizing (11) yields:

$$
\hat{h}_{q}=(1-d) h_{q} \hat{h}_{q-1}+S^{h} \hat{S}_{q}^{h}
$$

\section{An Agent-Based Approach to House Price}

In this Section we present the Agent-Based part of our model, where we adapt the Agent-Based framework in Lengnick and Wohltmann (2013) and Westerhoff (2008) to the housing market.

\subsection{Expectations}

As Adam, Marcet and Kuang (2011), we assume that households have correct beliefs (i.e., rational expectations) about all variables affecting their demand for housing services, except for the house price. Regarding the latter, they hold non rational beliefs.

More precisely, they can be either chartists $\tilde{E}_{t}^{c}(\cdot)$ or fundamentalists $\tilde{E}_{t}^{f}(\cdot)$. Chartists expect the price trend will continue, so their forecasting rule is given by:

$$
\tilde{E}_{t}^{c}\left[\hat{Q}_{t+1}\right]=\hat{Q}_{t}+l^{c}\left(\hat{Q}_{t}-\hat{Q}_{t-1}\right)
$$

where $\hat{Q}_{t}$ is the percentage deviation of house price from its steady state value at $t$ and the parameter $l^{c}>0$ represents the degree of "persistence" or trend-chasing in the house price expected 
by the chartists.

On the other hand, economic theory would suggest that the value of a house, as that of any asset, should be equal to the present discounted value of the expected returns from holding that asset. In our model, for fundamentalists this could be captured by equation (??):

$$
Q_{t}=\left(\frac{j_{t}}{h_{t}^{d, f}}+\gamma_{t} \theta Q_{t}\right)+(1-\tilde{d}) \delta \tilde{E}_{t}^{f} Q_{t+1}
$$

that has the usual asset pricing interpretation: the value of the asset is given by the dividend today plus the expected capital gain/loss tomorrow. The benefit today of holding the house is equal to the marginal utility provided by the housing services plus the utility deriving from the relaxation of the borrowing constraint, that is, $\left(\frac{j_{t}}{h_{t}}+\gamma_{t} \theta Q_{t}\right)$, while the capital gain tomorrow net of depreciation and discounting is $(1-\tilde{d}) \delta \tilde{E}_{t}^{f} Q_{t+1}$. One could then think of iterating forward equation (16) and find a value of the asset that depends on future expected "fundamentals", as one would do in a rational expectation framework. However, in our Agent-Based context it would not make sense to iterate this equation forward, simply because $\tilde{E}_{t}^{f} Q_{t+1}$ does not obey rational expectations. Hence we can not use equation (16) to calculate $\tilde{E}_{t}^{f} Q_{t+1}$ and then to substitute it iteratively forward in the same equation. So we need to find another route that it is coherent with the irrational beliefs of our agent based framework, where agents do not know the correct (and complex) determinants of house price dynamics. In addition, even expert economists in the real world rarely agree on the actual mechanism linking fundamentals to house prices.

Hence, we assume that households can not identify the true fundamental price. Similarly to Lengnick and Wohltmann $(2013,2016)$, that link the perceived steady state of the financial market to the aggregate economic activity, we link the fundamentalists' perceived fundamental price to the sectoral output, that is, to the supply of housing services. The idea is that fundamentalists understand that house supply depends on the expected price (see equation (13) in the previous Section). Hence, an increase in housing supply will then be interpreted by fundamentalists as a signal of the house builders reaction to an expected increase in the fundamental house price. ${ }^{10}$ Therefore, we assume that the perceived fundamental price at the beginning of each quarter is proportional to the amount of construction works that they observe. The latest available obser- 
vation to fundamentalists at the beginning of each quarter is the new housing built during the previous quarter, $S_{q-1}^{h}$. Hence:

$$
Q_{t}^{f d}=\text { const } * S_{q-1}^{h} \quad q=\text { floor }\left(\frac{t-1}{64}\right)
$$

The function $f l o o r(\cdot)$ simply rounds its argument to the nearest integers less than or equal to the argument itself, and it is simply used to divide the daily time scale into quarters, mapping the days $t$ into the respective quarters $q$. Note that $Q_{t}^{f d}$ is "fundamental" in the sense that both it depends on "fundamentals" and it moves at low frequency in the model, because it is constant over the quarter, being $\hat{Q}_{t}^{f d}=\hat{Q}_{q}^{f d}$. In log-deviations, (17) simply becomes

$$
\hat{Q}_{t}^{f d}=\hat{S}_{q}^{h}
$$

Therefore, fundamentalists believe that a fraction of the actual mis-pricing will be corrected in the future, so their forecasting rule is given by:

$$
\tilde{E}_{t}^{f}\left[\hat{Q}_{t+1}\right]=\hat{Q}_{t}+l^{f}\left(\hat{Q}_{t}^{f d}-\hat{Q}_{t}\right)
$$

where the parameter $l^{f}>0$ represents the fraction of the mis-pricing that fundamentalists expect to be corrected in the next period, and $\hat{Q}_{t}^{f d}$ is the perceived fundamental value.

To sum up, while chartists believe in a continuation of the recently observed house price trend, fundamentalists expect a reversal towards the perceived fundamental value.

Inserting (15) and (19) into (12) yields the chartists' demand function:

$$
\hat{h}_{t}^{d, c}=\widehat{j}_{t}+\frac{Q h^{d}}{j}\left[(1-\tilde{d}) \delta\left(\hat{Q}_{t}+l^{c}\left(\hat{Q}_{t}-\hat{Q}_{t-1}\right)\right)-\left(1+\delta \theta-\frac{\theta}{R}\right) \widehat{Q}_{t}-\frac{\theta}{R} \widehat{R}_{t}\right]
$$

and the fundamentalists' one:

$$
\hat{h}_{t}^{d, f}=\widehat{j}_{t}+\frac{Q h^{d}}{j}\left[(1-\tilde{d}) \delta\left(\hat{Q}_{t}+l^{f}\left(\hat{Q}_{t}^{f d}-\hat{Q}_{t}\right)\right)-\left(1+\delta \theta-\frac{\theta}{R}\right) \widehat{Q}_{t}-\frac{\theta}{R} \widehat{R}_{t}\right]
$$


The relative shares of chartists and fundamentalists are endogenously determined. Households learn about the past, and they change their beliefs according to the past performances of the two forecasting rules. Therefore, each group evaluates the attractiveness, $A_{t}^{i}$, of each forecasting rule on the basis of the following equation:

$$
A_{t}^{i}=\left[\exp \left(\hat{Q}_{t}\right)-\exp \left(\hat{Q}_{t-1}\right)\right] \hat{h}_{t-2}^{d, i}+\eta A_{t-1}^{i} \quad i=c, f .
$$

The attractiveness is thus partly related to the recent performance of the rule, measured by the term $\left[\exp \left(\hat{Q}_{t}\right)-\exp \left(\hat{Q}_{t-1}\right)\right] \hat{h}_{t-2}^{d, i}$, and partly by its past attractiveness, where $\eta \in[0,1]$ is the memory parameter.

The fraction of agents that adopt a particular strategy $\left(W_{t}^{i}\right)$ then is updated every day thanks to the Gibbs Probability, as in the framework of adaptive belief system proposed by Brock and Hommes (1997, 1998):

$$
W_{t}^{i}=\frac{\exp \left(e A_{t-1}^{i}\right)}{\sum_{i} \exp \left(e A_{t-1}\right)} \quad i=c, f
$$

The more attractive is a strategy, the higher is the fraction of agents using it. The parameter $e$ is called the rationality parameter: other things equal, the higher is $e$, the larger will be the number of agents that switches towards the strategy with the highest attractiveness.

\subsection{House Price Dynamics}

The deviation of the house price from its steady state, $\hat{Q}_{t}$, evolves according to:

$$
\hat{Q}_{t+1}=\hat{Q}_{t}+a\left(W_{t}^{c} \hat{h}_{t}^{d, c}+W_{t}^{f} \hat{h}_{t}^{d, f}-\hat{h}_{q-1}\right)+\varepsilon_{t}^{Q}
$$

(24) states that the change in the house price $\left(\hat{Q}_{t+1}-\hat{Q}_{t}\right)$ reacts to the excess of demand over supply in the housing market. This is given by the difference between the sum of the demand deviations of chartists $\hat{h}_{t}^{d, c}$ and fundamentalists $\hat{h}_{t}^{d, f}$ from the relative steady state, weighted by their relative shares $\left(W_{t}^{c}\right.$ and $W_{t}^{f}$ given by $\left.(23)\right)$, and the available supply of housing services, $\hat{h}_{t-1} \cdot{ }^{11} a$ measures the responsiveness of the house price to excess demand in the housing market. The noise term $\varepsilon_{t}^{Q}$ is an i.i.d. normally distributed shock with standard deviation $\sigma_{Q}^{2}$. It captures 
the idea that the two strategies are not the only possible strategies that exist into the market.

The quantity actually exchanged in the market obeys to the short side of the market, so it is given by the minimum between the sum of the chartists and fundamentalists demand in the correspondent quarter and the relative existing stock:

$$
G=\min \left\{\sum_{t=64(q-1)+1}^{64 q}\left(W_{t}^{f} \hat{h}_{t}^{d, f}+W_{t}^{c} \hat{h}_{t}^{d, c}\right) ; \hat{h}_{t-1}\right\}
$$

The actions of households and house builders are not synchronized, because demand and supply run on a different time scale. We assume that a quarter is composed by 64 days. Hence, within one increment on house supply's time index $q$, households perform 64 times their maximization problem generating their daily demand for houses. Therefore the model is implemented as follows: i) we run the daily demand for a quarter, given the shocks that hit the model; ii) then the quarterly price is equal to the mean of the daily price over that quarter; iii) we insert it into the supply equation to find the reaction of house builders and the new fundamental price; iv) we iterate.

A quarter is defined to contain days $64(q-1)+1, \ldots, 64 q$, for $q=1,2, \ldots$ :

$$
\hat{Q}_{q}=\frac{1}{64} \sum_{t=64(q-1)+1}^{64 q} \hat{Q}_{t}
$$

\section{The Model Simulation}

In this part of the paper we analyze the performance of the model. We use numerical simulations to investigate the ability of the model to generate fluctuations in the house price driven by endogenous waves of chartism and fundamentalism.

\subsection{Calibration}

The parameters calibration is reported in Table 1. As in Adam, Marcet and Kuang (2011), the annual discount factor $\delta$ is fixed at 0.96 and the annual depreciation rate at $3 \%$, implying: $d=0.0076$ and $\tilde{d}=1,19 \cdot 10^{-4} \cdot \alpha=0.4$ implies decreasing returns in production and captures 
the fact that housing is a capital-intensive sector. Parameter $\theta$ in the borrowing constraint is calibrated as in Iacoviello (2005). $\eta, e, l^{c}$ and $l^{f}$ are set as in Lengnick and Wohltmann (2013).

The value of the parameter $a$ in equation (24) is set to a lower value than in Lengnick and Wohltmann (2013). We argue that price elasticity to excess demand is much less in the housing market with respect to the financial market, because the house price is much more inertial and less volatile than asset prices in the financial market. Moreover, recall that the parameter $a$ in equation (24) measures the elasticity of the daily house price to the daily excess demand in the housing market, so it is reasonable to assume that the daily change of the house price responds very little to daily excess demand. Finally, it is worth noting that a low value is consistent with the finding in Bolt, Demertzis, Diks, Hommes and van der Leij (2014) that points towards an almost random-walk behavior of the deviation of the house price from equilibrium.

We calibrate the variance of the shock to the evolution of the house price in equation $(24), \sigma_{Q}^{2}$, so that the variance of the simulated quarterly price is the same as the variance of real quarterly price, collected by Federal Housing Finance Agency (http://www.fhfa.gov/).

\begin{tabular}{|c|c|}
\hline \hline \multicolumn{2}{|c|}{ Calibration } \\
\hline \hline$\alpha=0.4$ & $a=0.0007$ \\
\hline \hline$\delta=0.96$ & $l^{c}=0.04$ \\
\hline \hline$\theta=0.55$ & $l^{f}=0.04$ \\
\hline \hline$d=0.000119$ & $\eta=0.975$ \\
\hline \hline$e=300$ & $\sigma_{Q}^{2}=0.011$ \\
\hline \hline Table 1: Calibration of the model
\end{tabular}

\subsection{Waves of Chartism and Fundamentalism}

Following Lengnick and Wohltmann (2013), we simulate a representative run for a period of 40 quarters to show how the model works. We have two different sources of shocks in the model: the noise term on the house price equation $(24), \varepsilon_{t}^{Q}$, and a shock to the preference for housing services in the utility function, $j_{t}$. In this part of the paper, we analyze only the response of the system to repeated draw realizations of the noise term $\varepsilon_{t}^{Q}$, while keeping $\hat{\jmath}_{t}$ fixed at zero. The aim is 
to investigate how our Agent-Based framework interacts with the more standard partial dynamic model of households' choice.

Figure 1 shows the dynamics of the relevant variables: the top panel displays the daily house price along with the perceived fundamental value while the middle panel displays waves of chartism (black) and fundamentalism (white), labelled animal spirits.
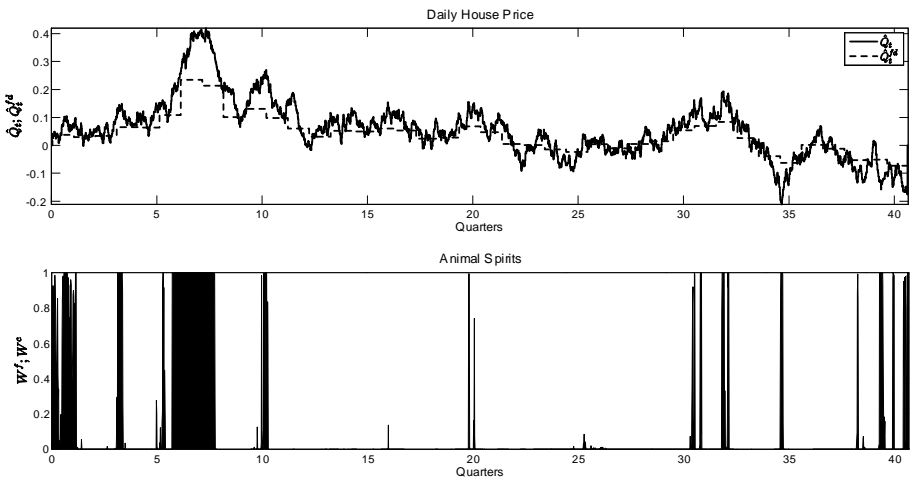

Figure 1: Representative run of the daily house price together with the perceived fundamental house price (upper panel), animal spirits (lower panel) representing the percentage of agents using the chartist (black area) or the fundamentalist (white area) expectation rule.

Figure 2 encompasses the dynamic of the quarterly house prices (top left) while the top right panel shows the evolution of housing stock. Finally the bottom left panel of Figure 2 shows the quantity actually exchanged on the housing market and the bottom right panel shows the housing stock, $\hat{h}_{q}$ (dashed line), and total demand, $W_{t}^{c} \hat{h}_{t}^{d, c}+W_{t}^{f} \hat{h}_{t}^{d, f}$ (solid line). The model is able to generate endogenous waves of chartism and fundamentalism, that in turn cause fluctuations in both the house price and quantity exchanged. While fundamentalists dominate for most of the time, in some particular periods the vast majority of agents follows the chartists' rule. When chartists prevail, the house price departs from its perceived fundamental value. As an example, quarters $q=6-9$ and $q=11-12$ exhibit a boom in the house price driven by chartists, while quarters $q=33-34$ exhibit a bust. In phases dominated by fundamentalists, on the contrary, the house price tends to go back to its fundamental value, which is evident for $q=13-18$ or $q=26-30$. 

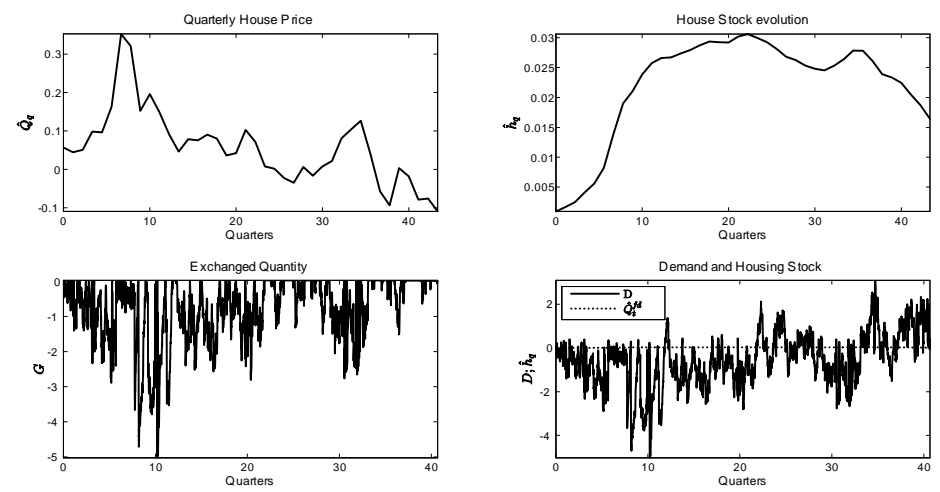

Figure 2: Representative run of the quarterly house price together with evolution of the housing stock (upper panel). In the lower panel we report the exchanged quantity together with the demand and supply dynamic.

Assume the house price starts trending upward, then the chartists' rule may outperform the fundamentalists' one strengthening and protracting the upward movement in the house price, and thus creating a boom. However, this sows the seeds for the subsequent bust. First, the supply of new houses increases with the price, and so does the available stock of housing. Therefore the excess demand tends to decrease, because the supply has a standard direct negative effect on the house price through equation (24). Second, the effect on demand of an increase in the house price depends on whether the negative substitution effect on demand (due to the increase in the current price) is offset by the positive wealth effect on demand (due to the increase in the expected future price). For chartists, the increase in the expected future price is due to the extrapolative expectations (equation (15)), while for fundamentalists this is due to the increase in the fundamental price caused the increase in the supply of new housing (equation (17)). Note the twofold role of an increase in supply: on the one hand, it forces a price decrease by increasing the stock of available houses, on the other hand it affects fundamentalists' expectations by increasing their perceived fundamental value, and thus their demand. Hence, on the one hand, the forces counteracting the lengthening of the boom phase are standard: the substitution effect on demand and the contribution of the supply of new houses to excess demand. On the other hand, the Agent-Based mechanisms of expectations formation both of chartists, who are trend follower on a daily basis, and fundamentalists, through the perceived fundamental price, contributes to the prolonging of the boom phase. Figure 3 clearly shows that the expected house price of chartist is 
more volatile than the one of fundamentalist. When the house price deviates from the perceived fundamental value, the chartist expectation rule produces a price forecast that largely deviates from the fundamental - e.g. during quarters 6-9. The variance of the expected house price implied by the chartist expectation rule is two times the one implied by the fundamentalist expectation rule. Note, however, that the fundamentalists' expectations tend to stabilize the price at high frequencies, because they tend to anchor the price to the perceived fundamental one which is fixed over the quarter. Indeed, Figure 1 shows that when fundamentalists dominate, the price tends to move towards the fundamental value.

Finally, the supply of new houses is closely influenced by the path of the quarterly house price (see the two top panels). The stock of existing houses, however, evolves very slowly because of the low depreciation rate. The exchanged quantity is the minimum between demand and the stock of existing housing stock. When there is excess supply, demand determines the quantity sold, and accordingly the time series is more volatile. On the contrary when supply drives the exchange quantity, the time series is represented by a broken line because this variable changes (very little) only at the end of each quarter.

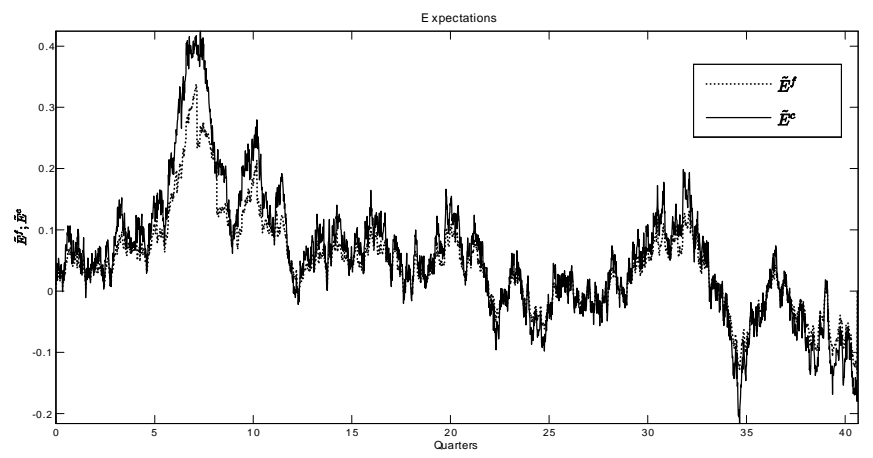

Figure 3: Representative run of the expected house prices by chartists and fundamentalists.

For sake of brevity, we refer to the Working Paper version of this manuscript for a sensitivity analysis regarding the parameters of the model. 


\section{Matching House Price Data}

In this Section we ask if the model is able to replicate the recent boom-and-bust house price dynamics in the US data. The aim is to identify the main driving forces of the dynamics of the house price according to our model. ${ }^{12}$ We want to see if our model can match the behavior of the quarterly house price for the period going from Q1:2004 to Q1:2009. The data, Seasonally Adjusted Purchase-only Index, are taken from the Federal Housing Finance Agency. We assume that in the initial period, i.e., Q1:2004, the system is in steady state. We then compute the percentage deviation of the quarterly house price from its steady state value.

Our framework can accommodate these three possible explanations through, respectively: i) the exogenous interest rate; ii) a time-varying value of $\theta$ in equation (3), as a proxy for credit tightness; iii) the exogenous preference shock, $j_{t}$, in the utility function. ${ }^{13,14}$

Regarding the interest rate we use the percentage deviation in 30-Years Conventional Mortgage Rate from its value in the initial period Q1:2004. As displayed in Figure 4 (upper left panel), this percentage deviation decreases steadily and substantially from 2004 to 2006, then it moves up and then down again, till it sharply increases from the Q2:2008. However, the change in this variable is rather small. We then fit this series into the demand functions of the two agents to see the resulting path of the house price. Results are shown in Figure 4 (upper right panel): the reaction of the model (dashed line) is very small compared with real data (solid line). To test for the "liberalization" story, we construct a path for the parameter $\theta$ in the borrowing constraint in the following way. First, we calibrate this parameter to be equal to Iacoviello (2005): $\theta=0.55$. Second, we consider the net percentage of banks reporting tightening credit standards in the US according to The January 2012 Senior Loan Officer Opinion Survey on Bank Lending Practices ${ }^{15}$. This measure (see Figure 4 middle left panel) remains stable from 2004 to the third quarter of 2006, when access to credit starts tightening quite substantially till the second quarter of 2008. Finally, we define $\theta_{t}$ as: $\theta_{t}=0.55-0.55 *$ tight credit, because the credit availability is an increasing function of $\theta$. The results of feeding this time-varying value of $\theta$ in our model are shown in Figure

4 (middle right panel). Again, it is clear that our model does not suggest this mechanism as the driving force of house price dynamics. Finally we consider the shock on house preferences $\hat{\jmath}_{t}$. To 
build a time series for $\hat{\jmath}_{t}$, we look at the quarterly table showing the Buying Condition for Houses in the Michigan Consumers Surveys. This measure is build from answers to the following question: Generally speaking, do you think now is a good time or a bad time to buy a house? We focus on the percentage of positive answers, and we normalized it to generate a series in a way to have figures in the subset $(-1,1)$. Figure 4 (bottom left panel) visualizes the resulting path for $\hat{\jmath}_{t}$. Values of the series higher than zero mean a positive preference shock, and vice versa. The shock is thus positive from 2004 to the first half of 2005, when it becomes negative and there remains till the end of our sample, even if reverts toward zero from the middle of the 2007. Figure 4 (bottom right panel) shows the response of the model to this path of the exogenous preference shock. In this case, our model economy is able to replicate the real price dynamics. In particular, the house price increase builds up very similarly to the data during the first two years and a maximum percentage deviation of house price is reached in the first half of 2006. After that the simulated time series exhibits a constant decline, while the data decrease slightly and then rise up again to a second maximum before starts decreasing. The simulated time series is not able to reproduce the mild twin-peaks in the data, and therefore the decrease in the simulated data happens 3 quarters before the one in the data. The rate of decrease after the peak, though, is quite similar.

Our analysis therefore suggests that by far the most important factor in the recent boom-bust dynamics of the house price in the US is a change in households' preference and housing demand. As such our analysis emphasizes the importance of the behavioral approach and of the selection mechanism among different expectation rules as determinant factors of the boom and bust cycle in the housing market. 

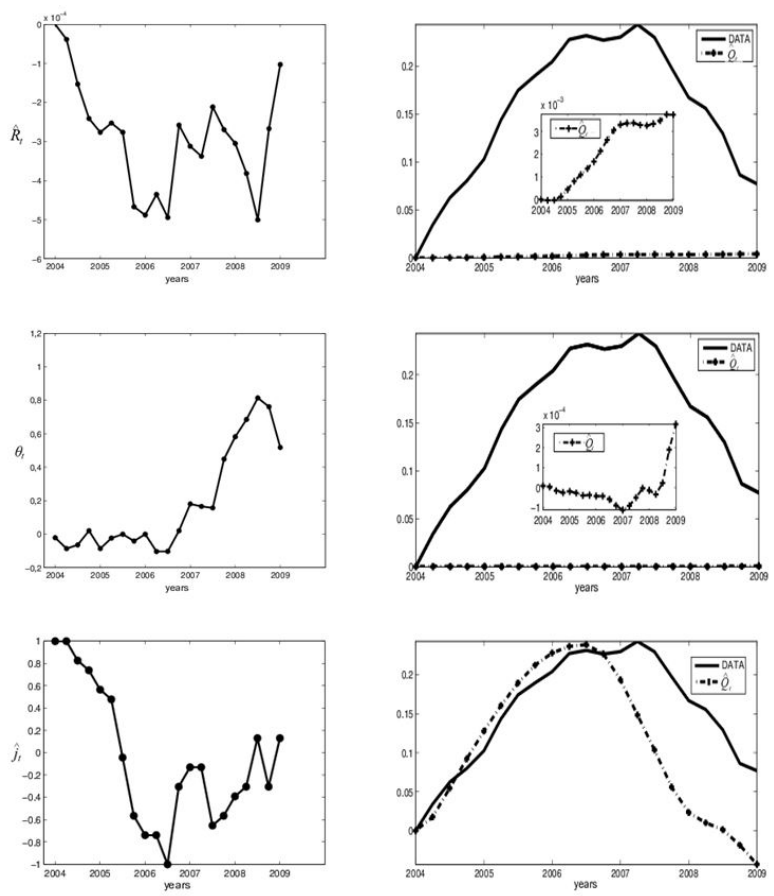

Figure 4: Percentage deviation of 30-Years Conventional Mortgage Rate, upper left panel. Model reaction to interest rate change, upper right panel. Net percentage of banks reporting tightening credit standard, left middle panel. Model reaction to credit tightening change, right middle panel. Preference shock, bottom left panel together with the Model reaction to preference shock, bottom right panel.

It is interesting to note that our result is consistent with the findings of Justiniano, Primiceri and Tambalotti $(2013)^{16}$, that employ a very different modeling strategy: more structural and less behavioral. They find that the dynamics of house price in the US could be explained by a "valuation" effect, that is an exogenous shock to preference for housing. On the contrary, like us, they find little role for the "liberalization cycle".

\section{Conclusion}

We developed a model to study the housing market starting from an Agent-Based perspective. We showed that it is possible to generate an endogenous creation of boom-and-bust dynamics in the house price by relaxing the rational expectation hypothesis, and embedding into the model an Agent-Based mechanism of evolutionary selection of expectation rules based on backward-looking 
behavior. The framework is based on the chartist-fundamentalist mechanism, and, despite its simplicity, it is able to match the behavior of US house prices quite well.

The results point to the exogenous preference shock as the main driving force behind the house price dynamics. On the contrary, the model suggests that other competing hypothesis, as a prolonged period of low interest rates or the liberalization in credit standards, have only minor effects on house price dynamics.

\section{Notes}

${ }^{1}$ guido.ascari@unipv.it

${ }^{2}$ nicolo.pecora@unicatt.it

${ }^{3}$ alessandro.spelta@unicatt.it

${ }^{4}$ To have a survey on the Agent-Based Computational models visit the Tesfatsion website, www.econ.iastate.edu/tesfatsi/ace.h

${ }^{5}$ We refer to the working paper version of this manuscript for an extended literature review about housing market models and bounded rationality.

${ }^{6} \mathrm{We}$ can assume income follows an exogenous stochastic process. In any case, the only role played by income is to pin down consumption (see equation (6)), which is not relevant for the analysis in the paper which focuses on house price dynamics.

${ }^{7}$ The quarterly house price is defined as an average of the daily prices over the quarter.

${ }^{8}$ Note that $d$ is the quarterly depreciation rate, so that: $1-d=(1-\tilde{d})^{64}$.

${ }^{9}$ Given our calibration $1+\delta \theta-\frac{\theta}{R}>0$.

${ }^{10}$ One can also argue that fundamentalists assume that house producers have superior information on the housing market, so they link $Q^{f d}$ to the observed $S^{h}$.

${ }^{11}$ Recall that the housing stock is constant over the quarter, because it changes only at quarterly frequencies. So: $h_{t}=h_{q}$ where $q=$ floor $\left(\frac{t-1}{64}\right)$.

${ }^{12}$ Other contributions, based on non-rational expectation, are able to match the data quite well: see, for example, Adam, Kuang, Marcet (2011).

${ }^{13} \mathrm{~A}$ preference shock for housing services as ours is also present in Iacoviello and Neri (2010), Liu, Wang and Zha (2011) and Justiniano, Primiceri and Tambalotti (2013).

${ }^{14}$ In this Section, shocks to the evolution of the house price, $\varepsilon_{t}^{Q}$, are muted in performing this impulse response type of exercise.

${ }^{15} \mathrm{http}: / /$ www.federalreserve.gov/boarddocs/snloansurvey/201201/default.htm

${ }^{16}$ See also Iacoviello and Neri (2010) and Kiyotaki, Michaelidies, and Nikolov (2010). 


\section{References}

[1] Adam, K., P. Kuang, and A. Marcet (2011) House price booms and the current account. In NBER Macroeconomics Annual 2011, Volume 26 (pp. 77-122). University of Chicago Press.

[2] Benito, A., and Mumtaz, H. (2009). Excess sensitivity, liquidity constraints, and the collateral role of housing. Macroeconomic Dynamics, 13(03), 305-326.

[3] Bolt, W., M. Demertzis, C. Diks, C.H. Hommes, and M. van der Leij (2014) Identifying Booms and Busts in House Prices under Heterogeneous Expectations. Mimeo, University of Amsterdam.

[4] Brock, W. A., and C.H Hommes (1998) Heterogeneous beliefs and routes to chaos in a simple asset pricing model. Journal of Economic dynamics and Control 22(8) 1235-1274.

[5] Brock, W. A., and C.H. Hommes (1997) A rational route to randomness. Econometrica 65(5) 1059-1095.

[6] De Grauwe, P., and P.R. Kaltwasser (2012) Animal spirits in the foreign exchange market Journal of Economic Dynamics and Control 36(8) 1176-1192.

[7] Eickmeier, S., and Hofmann, B. (2013). Monetary policy, housing booms, and financial (im)balances. Macroeconomic dynamics, 17(04), 830-860.

[8] Favilukis, J., S.C. Ludvigson, and S. Van Nieuwerburgh (2010) The macroeconomic effects of housing wealth, housing finance, and limited risk-sharing in general equilibrium. No. w15988. National Bureau of Economic Research.

[9] Gelain, P., K.J. Lansing, and C. Mendicinoc (2013) House Prices, Credit Growth, and Excess Volatility: Implications for Monetary and Macroprudential Policy. International Journal of Central Banking.

[10] Hommes, C.H. (2011) The heterogeneous expectations hypothesis: Some evidence from the lab. Journal of Economic Dynamics and Control 35(1) 1-24. 
[11] Iacoviello, M., and S. Neri (2010) Housing Market Spillovers: Evidence from an Estimated DSGE Model. American Economic Journal: Macroeconomics 2(2) 125-164.

[12] Iacoviello, M. (2005) House prices, borrowing constraints, and monetary policy in the business cycle. American economic review 95(3) 739-764.

[13] Justiniano, A., G.E. Primiceri, and A. Tambalotti (2015). Household leveraging and deleveraging. Review of Economic Dynamics 18(1), 3-20.

[14] Kiyotaki, N., A. Michaelides, and K. Nikolov (2011) Winners and losers in housing markets. Journal of Money, Credit and Banking 43(2-3) 255-296.

[15] Kiyotaki, N. and J. Moore (1997) Credit cycles. Journal of Political Economy 105(2) 211-248.

[16] Kontonikas, A., and A. Montagnoli (2006). Optimal monetary policy and asset price misalignments Scottish Journal of Political Economy 53(5) 636-654.

[17] Liu, Z., P. Wang, and T. Zha (2013) Land-price dynamics and macroeconomic fluctuations. Econometrica 81(3) 1147-1184.

[18] LeBaron, B. (2006) Agent-Based computational finance. Handbook of computational economics $2,1187-1233$.

[19] Lengnick, M., and H.W. Wohltmann (2013) Agent-Based financial markets and New Keynesian macroeconomics: A synthesis. Journal of Economic Interaction and Coordination 8(1) 1-32.

[20] Lengnick, M., \& Wohltmann, H. W. (2016). Optimal monetary policy in a new Keynesian model with animal spirits and financial markets. Journal of Economic Dynamics and Control $64(8)$ 148-165.

[21] Mian, A., and A. Sufi (2009) The consequences of mortgage credit expansion: Evidence from the US mortgage default crisis. The Quarterly Journal of Economics 124(4) 1449-1496.

[22] Naimzada, A, and M. Pireddu (2014) Dynamic behavior of product and stock markets with a varying degree of interaction. Economic modelling 41(21) 191-197. 
[23] Shiller, R.J. (2015) Irrational exuberance. Princeton university press.

[24] Shiller, R.J. (2012) The subprime solution: How today's global financial crisis happened, and what to do about it. Princeton University Press.

[25] Shiller, R.J. (2008) Historic turning points in real estate. Eastern Economic Journal 34(1) 1-13.

[26] Shiller, R.J. (2007) Understanding recent trends in house prices and home ownership. No. w13553. National Bureau of Economic Research.

[27] Tversky, A., and D. Kahneman (1973) Availability: A heuristic for judging frequency and probability. Cognitive psychology 5(2) 207-232.

[28] Westerhoff, F.H. (2012) Interactions between the real economy and the stock market: A simple agent-based approach. Discrete Dynamics in Nature and Society, 2012.

[29] Westerhoff, F.H. (2008) The use of Agent-Based financial market models to test the effectiveness of regulatory policies. Jahrbucher Fur Nationalokonomie Und Statistik 228(2) 195-227. 